\section{In plain English: No euthanasia please}

Why are Downar and colleagues ${ }^{1}$ so coy? Why not write in plain English? They come down squarely in favour of physician-assisted death, but don't most physicians already assist in death? The authors, ${ }^{1}$ presumably, are promoting physician-administered death. The authors have moved "beyond Yes or No" to advocate euthanasia, but they do not want to admit this. They tell us to forget our well-rehearsed debate: sanctity of life versus patient autonomy, and yet they say they have no clear answer to their question of how to protect the vulnerable or incapable from receiving physician-administered death against their will. Psychiatric indications for physician-administered death by lethal injection could be equally contraindications.

The authors" ask, "How can we ensure that physician-assisted death is available equitably to all patients?" Very simply, if amyotrophic lateral sclerosis or metastatic cancer are potential indications for physician-assisted death, then it will have to be offered to all patients with such diseases. A few will accept, many will be frightened and a few will feel obliged. Obviously, there would be a trade-off. The supposed benefit to a few would threaten many more: this is why most doctors oppose euthanasia. Do the authors ${ }^{1}$ have any new figures to contradict this? In my 29 years of experience, the vast majority of the frail and ill want to live - and without a medically administered threat hanging over them.

The authors" ask, "How can we ensure that physician-assisted death will not be considered a low-cost alternative to palliative care?" There is only one way: do not make killing the patient an alternative. Indeed, the authors do suggest the answer: improve the availability of palliative care and keep physician administered-death illegal.

\section{Nicholas M. Newman MD}

Department of Orthopaedics, University of Montreal, Montréal, Que.

\section{Reference}

1. Downar J, Bailey TM, Kagan J, et al. Physicianassisted death: time to move beyond Yes or No. CMAJ 2014;186:567-8.

CMAJ 2014. DOI:10.1503/cmaj.114-0049

\section{Premature closure of the debate}

Downar and colleagues ${ }^{1}$ are premature in their assertion that the "Yes or No" debate about euthanasia and physicianassisted death is over.

As the authors note, last August the Canadian Medical Association (CMA) voted against a change in its policy, which opposes physician-assisted death. The CMA's blog on this issue is running at least two to one against physician-assisted death; an even larger proportion of Downar's palliative care colleagues are opposed. ${ }^{2}$ Whatever the courts may decide, apparently, the majority of Canadian physicians are unwilling to participate in physicianassisted death or euthanasia.

Downar and colleagues ${ }^{1}$ provide a comprehensive list of the controversies that may arise should physicianassisted death be legalized in Canada. I wish to respond to 2 of the 13 questions in the list:

"How can we protect the vulnerable?" We can't. It's too short a step from believing that one might choose physician-assisted death to believing that it should be chosen; the vulnerable will inevitably feel a sense of coercion.

"How can we ensure that physicianassisted death will not be considered a low-cost alternative to palliative care?" We can't. Despite the experience in Oregon in this regard, the much larger experience in the Netherlands has been an untoward delay in the development of palliative care services. ${ }^{3}$ When faced with a difficult palliative case, it's just too easy to say, "Why bother?"

This debate is not over. For the sake of our most vulnerable patients, and for the sake of our colleagues, especially our youngest colleagues, we must persevere.

\section{Howard Bright MD}

Family physician, Chilliwack, BC

\section{References}

1. Downar J, Bailey TM, Kagan J, et al. Physicianassisted death: time to move beyond Yes or No. CMAJ 2014;186:567-8.

2. Lapointe B, Borod M, Mount B. Opinion: Palliative-care providers oppose Bill 52, Quebec should listen. The Gazette (Montréal) 2013 Oct. 11. Available: www.ehospice.com/canadaenglish/Default /tabid/10678/ArticleId/7094 (accessed 2014 May 5).

3. Gorijn B, Jannssens R. Euthanasia and palliative care in the Netherlands: an analysis of latest developments. Health Care Anal 2004;12:195-207.

\section{CMAJ 2014. DOI:10.1503/cmaj.114-0050}

\section{The authors respond}

Newman ${ }^{1}$ and Bright ${ }^{2}$ both express concerns about the messages of our article, ${ }^{3}$ but neither appears to have understood them correctly.

We did not express support for, or opposition to, legalization of physicianassisted death. We posed questions that we feel should be addressed about the practical aspects of performing legal physician-assisted death in Canada. Newman ${ }^{1}$ suggests we are coy in our use of the term "physician-assisted death," but we explicitly defined this term in the first sentence of our article as including both euthanasia and assisted suicide. The term "physicianassisted death" is widely used, including by Justice Smith in the Carter case. ${ }^{4}$

We did not assert that the "Yes or No" debate was "over." We pointed out that the debate will be practically obsolete if physician-assisted death becomes legal by judicial or legislative means, and that physicians have a professional responsibility to prepare for this possibility regardless of whether they support legalization.

We share Newman ${ }^{1}$ and Bright's ${ }^{2}$ concern about the potential effects on the vulnerable. But we are reassured by data from the Netherlands that suggest that involuntary euthanasia became less common after legalization of physicianassisted death, ${ }^{5}$ and data from Switzerland $^{6}$ and the United States ${ }^{7}$ that show that vulnerable populations are less likely to receive physician-assisted death.

Newman ${ }^{1}$ asserts that the only way to safeguard against the use of physician-assisted death as a cost-saving measure is to ban it. This argument seems to imply a lack of commitment by physicians and other health care 